\title{
Robótica, realidad aumentada y TAC como herramientas clave en la metodología CLIL en Educación Infantil
}

\section{Using robots, augmented reality and ICT in a CLIL preschool classroom}

\author{
María Cristina Moral, Elena Moreno Fuentes*
}

Recibido: 27 de noviembre de 2020 Aceptado: 3 de junio de 2021 Publicado: 27 de julio de 2021

To cite this article: Moral, M.C; Moreno Fuentes, E. (2021). Robótica, realidad aumentada y TAC como herramientas clave en la metodología CLIL en Educación Infantil. Márgenes, Revista de Educación de la Universidad de Málaga. 2 (2), 116-129 DOI: $\underline{\text { http://dx.doi.org/10.24310/mgnmar.v2i2.10908 }}$

\section{RESUMEN}

Presentamos en este artículo una experiencia de aula en la que se trabaja la metodología CLIL (Content and Language Integrated Learning) en educación infantil utilizando las tecnologías digitales como recurso educativo. El objetivo principal de dicha experiencia es llevar la metodología CLIL a los proyectos de trabajo que los alumnos/as ya estén realizando en su lengua materna y emplear las TAC como recursos clave para el desarrollo de las habilidades comunicativas del alumnado. De esta forma, el aprendizaje de los contenidos propios del currículum y el desarrollo de la competencia en la lengua extranjera se realizan de forma paralela, sin ningún tipo de división temporal, espacial o didáctica.

Palabras clave: robótica; CLIL; TAC; infantil; realidad aumentada

\section{ABSTRACT}

In this article we present a class innovative experience where we work on CLIL methodology (Content and Language Integrated Learning) in preschool education by means of Information and Communication Technologies. The main objective of this experience is to develop CLIL methodology together with a project-based approach and introducing robots and augmented reality as a source of knowledge. By means of using CLIL and projects, we develop linguistic competence on students and we work on content in a more meaningful way.

Keywords: robots; CLIL; ICT; preschool; augmented reality

\section{INTRODUCCIÓN}

La presente experiencia educativa se basa en la incorporación de la metodología CLIL (Content and Language Integrated Learning) en el aula de educación infantil utilizando las nuevas tecnologías como recurso educativo. Esta propuesta educativa surge tras observar que diversos centros 
educativos, cuya metodología se basa en el Aprendizaje Basado en Proyectos (ABP) y que desarrollan dos proyectos de trabajo diferentes: uno destinado al área de lengua extranjera (inglés) y otro al resto de áreas curriculares. Como respuesta a esto, surge esta práctica de innovación educativa, cuyo principal objetivo es llevar la metodología CLIL a los proyectos de trabajo que los alumnos estén realizando en su lengua materna. De esta forma, el aprendizaje de los contenidos propios del currículum y el desarrollo de la competencia en la lengua extranjera se realizan de forma paralela, sin ningún tipo de división temporal, espacial o didáctica donde, además, se introducen las TAC (Tecnologías de la Información y la Comunicación) como recurso educativo.

El presente trabajo está estructurado en tres partes principales: en primer lugar, se recoge un estado de la cuestión centrado en las TAC y en la metodología CLIL. En segundo lugar, detalla la práctica de intervención: los objetivos, la metodología aplicada, las actividades llevadas a cabo y la evaluación de la innovación. Por último, se expone una conclusión, tanto de lo que se ha logrado como de las limitaciones que presenta esta práctica de innovación.

\section{MARCO TEÓRICO}

El término CLIL fue acuñado en 1994 por David Marsh, entre otros, como un término general que podría abarcar una amplia gama de situaciones relacionadas con "la experiencia de aprender materias no lingüísticas a través de una lengua extranjera” (Marsh, 2002, p. 28). En español, el término se ha denominado AICLE (Aprendizaje y Enseñanza de Lenguas Extranjeras). Tal y como señala Brown (2006, p.91), hay una "multitud de razones” por las que los niños/as pueden tener dificultades para adquirir una segunda lengua, incluyendo los complejos factores personales, sociales, culturales y políticos. En respuesta a esto, el enfoque CLIL puede ofrecer mayores y oportunidades que aporten mucha más flexibilidad a la hora de mejorar el aprendizaje de idiomas. Del mismo modo, Marsh (2000) argumenta que CLIL ofrece oportunidades más realistas y naturales para aprender y usar una lengua adicional de tal modo que los alumnos/as no son conscientes de estar aprendiendo la lengua como tal, sino que se centran solo en aprender el contenido. Dicho esto, el lenguaje es un ingrediente clave para el éxito en un mundo cada vez más "interconectado por el intercambio de información y conocimiento" (Mehisto, Marsh y Frigols-Martín, 2008, p.10).

Si entendemos la metodología CLIL (Marsh, 2002) como un conjunto de situaciones en las que las materias, o partes de estas, se enseñan utilizando como vehículo de comunicación una lengua extranjera, podemos enumerar algunos de los beneficios que supone su implementación en las aulas. En primer lugar, a través del uso de CLIL en el aula se producen situaciones reales de comunicación en las que los alumnos/as deben poner en práctica ciertas estrategias lingüísticas. En otras palabras, el alumnado se encuentra inmerso en la lengua meta, dando lugar a la mejoría de su competencia lingüística, especialmente en las destrezas relacionadas con el nivel oral. En segunda instancia, hemos de destacar que a través de esta metodología se fomentan valores como la empatía, el interés, el respeto o el disfrute por la diversidad cultural y lingüística, incrementando y facilitando el conocimiento intercultural. Y, tal y como señala Coalla (2014), hemos de destacar que usando esta metodología aumenta la motivación y confianza en el alumnado. 
Sin embargo, la rápida expansión de esta metodología ha dado lugar a ciertas dificultades para su implantación en las aulas. Uno de los problemas a considerar es la falta de formación en el profesorado. Así, por ejemplo, existen casos en los que el profesorado presenta un dominio avanzado de la lengua extranjera pero no se encuentra habilitado para impartir los contenidos de otras áreas (matemáticas, artes, medio social y cultural, etc.) $\mathrm{O}$ por bien, encontramos situaciones en los que el profesorado está capacitado para impartir los contenidos de las diferentes áreas del currículum, pero no presenta el dominio necesario en la lengua extranjera (Suárez, 2005).

En los últimos años, las universidades, las editoriales y las instituciones privadas han desarrollado programas formales e informales de formación de docentes CLIL. Sin embargo, a pesar de estas iniciativas, el significado de CLIL sigue siendo un misterio para muchos maestros/as. Además, hemos constatado muy pocos programas en CLIL han sido diseñados para la etapa de infantil. En la práctica, los perfiles de los docentes a los que se les ha encomendado la entrega de programas CLIL varían considerablemente dependiendo del país. Por lo tanto, el área de formación de docentes de CLIL necesita un fortalecimiento y consolidación sustancial para garantizar que los educadores estén preparados para ayudar a sus alumnos a convertirse en agentes calificados, plurilingües y pluriculturales equipados y preparados para formar al alumnado a ser capaces de enfrentarse al mundo globalizado en el que vivimos.

Del mismo modo, resulta interesante destacar que CLIL no se implementa de igual forma en los distintos niveles educativos y que, en el caso de la educación infantil, se recomienda que los maestros/as se centren particularmente en aquellos aspectos que van relacionados al desarrollo natural del niño/a, por lo tanto, es indispensable usar la repetición y la imitación, estimular los sentidos, permitir y favorecer el juego y la manipulación de objetos. A medida que los alumnos/ as progresan y pasan a la etapa preoperativa, los docentes de infantil necesitan generar confianza, continuar permitiéndoles manipular objetos, usar refuerzo positivo, alentar preguntas, proporcionar dibujos e historias simples que estimulen los sentidos (Santrock, 2005).

Aunque son escasos los modelos o metodologías formales que han surgido para implementar CLIL con estudiantes de Educación Infantil, autores como Coyle et al. (2010) han observado que CLIL para estudiantes de este nivel sería similar en muchos aspectos a los enfoques existentes para el aprendizaje de idiomas en infantil; dado que estos alumnos/as se centran principalmente en realizar acciones, el empleo de actividades donde se lleven a cabo acciones (como jugar, cantar, dibujar y construir modelos) puede ser muy apropiado y eficaz. Cabe señalar que, a este nivel, los docentes tienen un importante, quizás único, impacto como modelos a seguir para la comunicación oral y, por lo tanto, deben ser maestros/as con un alto grado de fluidez, aunque no se requieren necesariamente características de pronunciación "nativas”.

Por otro lado, ciertamente, hemos de señalar que existe una falta de recursos o materiales didácticos CLIL para la etapa infantil lo cual resulta un escollo para el profesorado que utiliza esta metodología; algunas editoriales han traducido y adaptado libros de texto tradicionales al idioma extranjero, dando lugar a la disminución de la eficacia de CLIL (Loyola, 2013). Para crear materiales adecuados para CLIL, Coyle (2008) desarrolla una base teórica y metodológica para la planificación y construcción de materiales CLIL, la cual se conoce como las 4Cs-Framework. Esta base teórica se fundamenta en los siguientes principios (Coyle, 2002, p. 543). En primer lugar, define el concepto de contenido donde destaca que el objetivo de esta metodología no es solo adquirir 
los conocimientos y habilidades sino que se trata de que los alumnos creen sus propios conocimientos y habilidades. Tras esto, se explica el concepto de cognición a través del cual establece una conexión entre el contenido y su relación con el pensamiento, de esta forma, permitiremos que los estudiantes realicen su propia interpretación del contenido mediante el análisis de las demandas lingüísticas de éstos. En tercer lugar, Coyle (2008) explica el concepto de comunicación en CLIL haciendo referencia al hecho de que el lenguaje debe aprenderse relacionado con el contexto de aprendizaje y que la única forma de llegar a conocer el contenido es a través del lenguaje. Finalmente, el concepto de cultura donde destaca que la relación entre culturas e idioma es compleja y que el desarrollo de una conciencia intercultural es fundamental para CLIL.

En este sentido, hemos de destacar que un pilar fundamental en el que podemos apoyar el diseño y uso de los materiales para la metodología CLIL en infantil es en el empleo de las nuevas tecnologías que han cambiado nuestra sociedad, $y$, en consecuencia, han dado lugar a cambios en los modelos de enseñanza-aprendizaje puesto que la educación no puede permanecer impasible ante los cambios sociales.

Organismos como la UNESCO (Pinagorte y Ramirez, 2018, p.3) consideran a la ciencia y a su aplicación un pilar fundamental para el crecimiento y mejora de la calidad de vida de los habitantes de un país. Asimismo, la UNESCO demanda su integración en la formación del alumnado infantil las innovaciones tecnológicas que permita el desarrollo de competencias importantes para la vida. De esta forma, se enumeran algunas de ellas como el saber observar, analizar, identificar, formular hipótesis, preguntas e investigar desde edades tempranas. Otros autores como Orcera, Moreno y Risueño (2017, p.159) destacan que en relación con la integración de las tecnologías del aprendizaje y del conocimiento (TAC) en un aula CLIL "las tecnologías (..) forman parte de nuestra vida cotidiana (...) El proceso lógico es integrarlas en los espacios escolares, aprovechando sus ventajas para impartir un área en una lengua extranjera”.

De igual manera, para Salinas (2004) es imprescindible que los docentes entiendan que su rol también cambia en un ambiente con una amplia presencia de tecnologías. En este caso, el profesor deja de ser la fuente de todo conocimiento y pasa a actuar como guía de los alumnos, mientras que les facilita el uso de los recursos y las herramientas que necesitan para explorar y elaborar nuevos conocimientos y destrezas; el docente pasa de ser el gestor de los recursos de aprendizaje a un tener un papel de orientador y mediador.

Las revolución tecnológica que hemos experimentado a lo largo del siglo pasado (la prensa, la televisión y más recientemente, el surgimiento de la llamada cultura digital) ha tenido un importante impacto en la educación. De este modo, en el empleo de la metodología CLIL en infantil, las TAC resultan ser una plataforma ideal para el desarrollo de estrategias y metodologías interactivas que ayuden a promover el aprendizaje autónomo, la interacción entre iguales y el uso del lenguaje para fines comunicativos.

Dicho brevemente, los beneficios relacionados con el uso de las TAC en las aulas no se manifestarán en el alumnado si solo se cambian las herramientas de enseñanza, también se debe cambiar la metodología. Si el profesor sigue el temario del libro de texto y simplemente realiza alguna incorporación de las nuevas tecnologías, éstas apenas tendrán impacto en los alumnos. El profesor debe usar las TAC y las posibilidades de comunicación que estas ofrecen al alumnado 
para recabar información y transformarla en conocimiento, sólo de esta forma los alumnos se beneficiarán de las posibilidades que ofrecen estos nuevos recursos.

En este sentido, hemos de destacar la introducción de las TAC que se han implementado en esta experiencia de aula; en especial, se ha trabajado extensamente con realidad aumentada y robótica en infantil para promover el aprendizaje de los contenidos CLIL.

En primer lugar, cuando hablamos de realidad aumentada (RA) nos referimos a una tecnología que aumenta el mundo físico real con imágenes 3D virtuales generadas por ordenador, teléfono móvil o tableta. De este modo, la RA no sustituye el mundo real por uno virtual, sino que lo complementa a base de aumentarlo y ofrecer ciertas funcionalidades extra a las imágenes que se proyectan a través de los dispositivos móviles. En lo referente al mundo educativo, permite proporcionar el visionado de contenidos didácticos que son totalmente inviables con otras tecnologías. Tal y como señalan Moreno y Pérez (2017, p.57) trabajar con dispositivos móviles y con RA “aumenta la motivación del alumnado, resultando una práctica cercana y cotidiana, de fácil uso y que logra la implicación de todos”.

A pesar de que el alumnado de infantil se encuentra rodeado de un entorno totalmente virtual y enriquecido por la tecnología, el currículo escolar no se centra especialmente en la exploración de este mundo digital hasta los últimos cursos de la etapa de primaria. Son pocos los países que han establecido políticas y líneas de actuación claras para introducir la tecnología en el currículo en estas etapas iniciales (Siu y Lam, 2003). De este modo, se aprecia que el currículo en infantil en el área de ciencias se centra mucho más en el conocimiento del entorno natural a través de aspectos como las plantas, los animales o el clima. Sin duda, este aprendizaje resulta clave en infantil, aunque Bers (2008) destaca también la esencialidad de comprender el mundo tecnológico y digital que nos rodea.

Si miramos a nuestro alrededor, el alumnado de infantil está rodeado de sensores cada vez que acciona un grifo automático o que entra en una habitación con un sensor de luz (Bers y Horn, 2010), así pues constatamos que esta fusión de electrónica y tecnología no es ajena al niño/a sino que está integrada en su realidad cercana. De este modo, la robótica ofrece la posibilidad de enseñar al alumnado de las primeras etapas acerca de los sensores, de la electrónica y de la tecnología que les rodea como parte de ese entorno natural del área de ciencias del que se hablaba anteriormente. De este modo, enseñar a través de la robótica y del uso de la programación facilitan y propician que el alumnado comprenda cómo funciona este mundo digital que les rodea.

\section{PUESTA EN PRÁCTICA DE LA EXPERIENCIA DE AULA}

La práctica de innovación educativa que se presenta tiene como objetivo llevar a cabo una tarea dentro del proyecto de trabajo "El fondo del mar", el cual estaban realizando los alumnos de infantil en ese momento. Esta tarea utiliza como vehículo de comunicación la lengua extranjera inglesa, desarrollando así la metodología AICLE en las aulas de Educación Infantil. Además, se ha introducido el uso de diferentes aplicaciones, herramientas y recursos tecnológicos, empleando así las TAC como recurso educativo y como elemento motivador en el proceso de enseñanza-aprendizaje. 
El Centro Educativo Escuelas Profesionales de la Sagrada Familia (Úbeda) ha sido el lugar en el que se ha llevado a cabo la práctica de innovación. Este centro cuenta con un programa de enseñanza bilingüe llamado Ágora Communicative el cual persigue un doble objetivo; mejorar el bilingüismo del alumnado y su desarrollo cultural y profesional en la sociedad actual. Dicho programa se basa en la metodología CLIL y los alumnos tienen la oportunidad de participar en él desde el primer curso del segundo ciclo de Educación Infantil (3 años).

Así mismo, en la etapa de Educación Infantil, este centro trabaja a través de la metodología ABP (Aprendizaje Basado en Proyectos). Podemos definir esta metodología como aquella en la que el aprendizaje se basa en un conjunto de tareas que dan respuesta a preguntas y/o problemas planteados por el alumnado, teniendo en cuenta sus intereses y motivaciones. Sin embargo, cabe mencionar que, en el centro educativo, para el desarrollo de la lengua extranjera (inglés) se realiza un proyecto de trabajo diferente al que llevan a cabo en el aula ordinaria, es decir, en su lengua materna. Fue tras analizar estas características que consideramos la idea de llevar a cabo la metodología CLIL dentro del proyecto de trabajo que el alumnado estaba desarrollando en su lengua materna, además de utilizar las TAC como un recurso más en este proceso de enseñanza - aprendizaje.

De forma que el principal objetivo de esta práctica de innovación ha sido aunar el proyecto de trabajo "El fondo del mar" con la metodología CLIL, llevando al aula las nuevas tecnologías como recurso educativo. Por otra parte, dentro de este objetivo se enmarcan otros más específicos;

- Reflexionar sobre el uso de las nuevas tecnologías y la metodología CLIL en las aulas de Educación Infantil.

- Aumentar la motivación de los alumnos hacia el aprendizaje de la lengua extranjera.

- Crear un clima de participación y confianza dentro del aula para fomentar la autoconfianza y motivar al alumnado a participar.

- Usar las TAC para incrementar la motivación hacia la lengua inglesa.

- Evaluar si se ha conseguido este objetivo a través de la observación directa.

- Mejorar la competencia comunicativa en la lengua extranjera, concretando a nivel oral.

- Programar actividades en las que sea necesario comunicarse entre los iguales o en la asamblea.

- Usar las nuevas tecnologías para crear actividades y experiencias que desarrollen la competencia comunicativa a nivel oral.

- Evaluar tanto el nivel de participación del alumnado como el producto obtenido tras realizar las actividades.

- Promover el uso de la tecnología como elemento facilitador del aprendizaje de contenidos a través de la lengua extranjera.

- Programar actividades relacionadas con el fondo del mary donde se usen las TAC.

- Conocer vocabulario y expresiones básicas en inglés, relacionadas con el fondo del mar.

- Evaluar, a través del producto final, la adquisición de dicho vocabulario y expresiones orales. 
Por último, en cuanto a la temporalización, la práctica de innovación se ha llevado a cabo en tres sesiones de 45 minutos cada una de ellas. El espacio utilizado en cada una de estas sesiones ha sido el aula destinada al desarrollo de la lengua inglesa, dando así sentido al uso de la lengua inglesa durante un proyecto que de forma usual el alumnado estaba trabajado en su lengua materna; la práctica realizada ha permitido incorporar estas sesiones a la marcha del proyecto haciéndolas exclusivamente en inglés. A continuación, se detallan las actividades que se han realizado con el alumnado de tercer curso de Educación Infantil para poder poner en práctica esta innovación.

\subsection{Primera sesión: Voki y Quiver}

Para contextualizar el uso de la lengua inglesa en el proyecto de trabajo "El fondo marino" y para motivar al alumnado, en esta primera sesión hemos presentado la tarea al alumnado a través de la página web Voki. Esta aplicación nos ha permitido transmitir al alumnado un mensaje a través de un pez, el cual ha sido un recurso para contextualizar la tarea e iniciar y motivar al alumnado en la realización de las diferentes actividades que se llevaron a cabo en las siguientes sesiones.

El mensaje, que se ha reproducido en la pizarra digital, ha sido el siguiente: Hello, I am a fish. Do you want to know my friends? Los alumnos, tras comprenderlo, han mostrado mayor interés en las actividades que venían a continuación, lo cual nos ha permitido aumentar la motivación por la realización y aprendizaje de los contenidos que se presentaron en las sesiones posteriores.

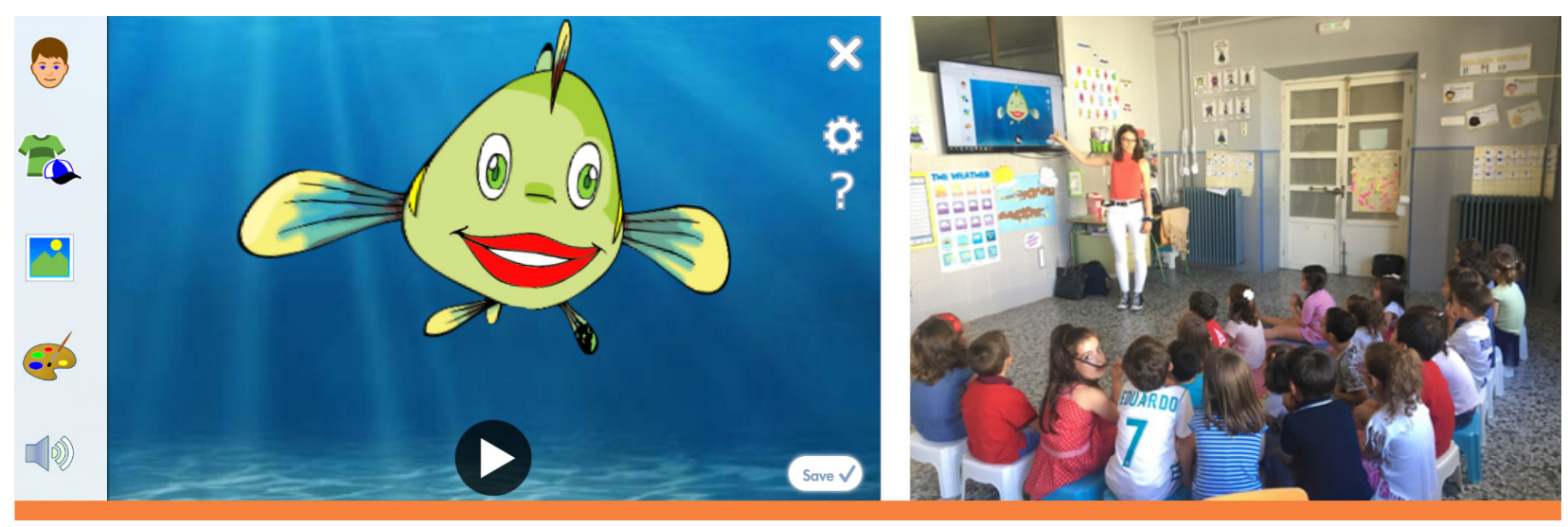

Figura 1. Imágenes de la emisión del mensaje creado a través de la página web Voki. El centro ha permitido la publicación de todas las imágenes del documento

Una vez que hemos despertado el interés del alumnado por conocer el resto de animales del fondo del mar, han aparecido en la pantalla seis animales marinos y les han realizado la siguiente pregunta; Who am I? Algunos de los alumnos conocía el nombre de estos animales en inglés por lo que han participado y compartido su conocimiento sobre la lengua con el resto de compañeros, sin embargo, no conocían todos los animales que se les ha mostrado por lo que nos ha servido como enlace para enseñar los flashcards y, de esta manera, ampliar el conocimiento de los alumnos sobre este vocabulario. 


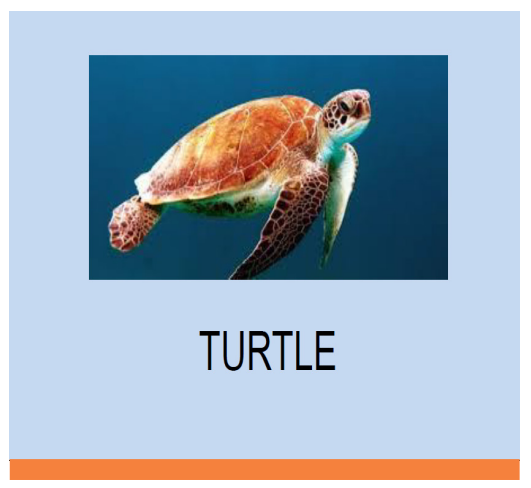

Figura 2. Ejemplo de Flashcards utilizados a lo largo de la tarea
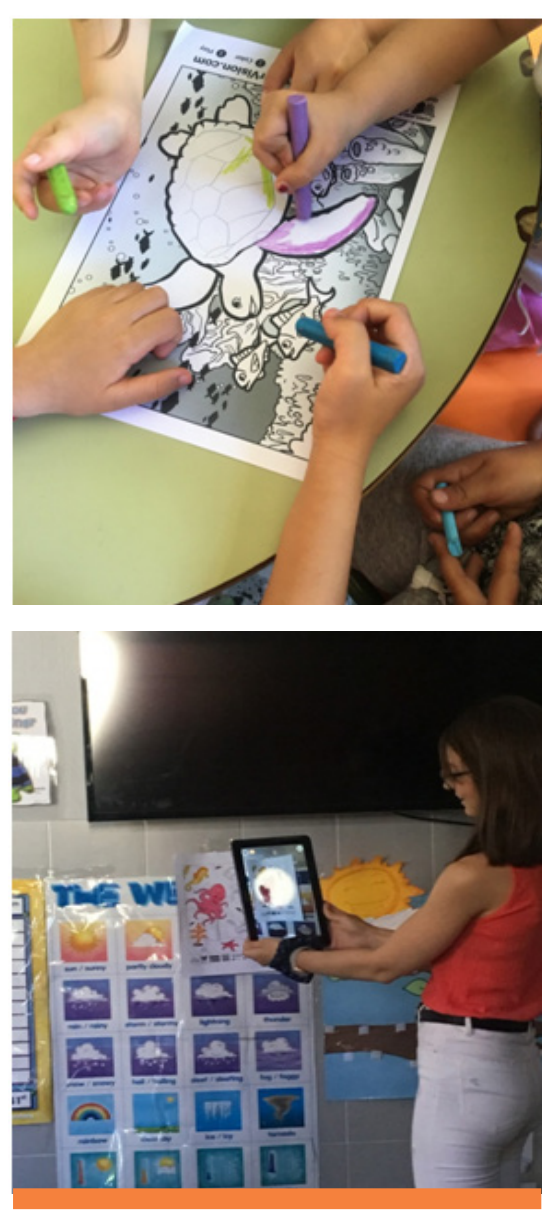

Figura 3. Puesta en práctica de la aplicación Quiver
Para finalizar esta primera sesión, hemos utilizado la aplicación Quiver. El primer paso para poder llevar a cabo esta actividad ha sido que los alumnos coloreen los animales del fondo del mar que les hemos proporcionado. Una vez que los han terminado, hemos escaneado las imágenes a través de las tablets y han aparecido estos animales en tres dimensiones. Mientras que los alumnos observaban sus producciones en 3D, les proporcionamos input oral con preguntas y expresiones como: “What animal is this? Look, a shark!”. De esta forma, hemos reforzado el vocabulario visto a través de los flashcards, desde el punto de vista lúdico, participativo y significativo para el alumnado, han aprendido y reforzado los diferentes animales marinos en la lengua inglesa a partir de sus reproducciones.

\subsection{Segunda sesión}

Esta segunda sesión, al igual que la anterior, ha comenzado mostrando los flashcards al alumnado para afianzar así el vocabulario propio de esta tarea. Caben destacar algunas actividades que hemos llevado a cabo con este recurso, algunas de ellas son; quitar alguno de los animales que tenemos en los flashcards y que los alumnos digan, en la lengua inglesa, el animal que falta, decir el vocabulario en inglés y que ellos lo traduzcan a su lengua materna o darle a un alumno los tarjetas y que éste ejerza el rol de docente, es decir, debe decir el animal marino en inglés para que el resto de compañeros repitan este animal... Una vez que hemos jugado y aprendido a través de los flashcards hemos utilizado el robot Next 1.0. Este robot permite al alumnado iniciarse en el lenguaje de la programación y despierta en el alumnado el interés por las nuevas tecnologías. Algunos beneficios que debemos destacar relacionados con el uso del robot pueden ser:

- Mejorar la capacidad de atención y concentración.

- Estimular la organización y comprensión.

- Reforzar la lógica y el cálculo.

- Potenciar la autonomía y el interés por la experimentación.

Next 1.0 funciona a través de la programación de órdenes muy sencillas (derecha, izquierda, delante o atrás). Presionando los diferentes botones, los alumnos pueden introducir una secuencia de comandos al robot, que quedarán almacenados en su memoria secuencial. 

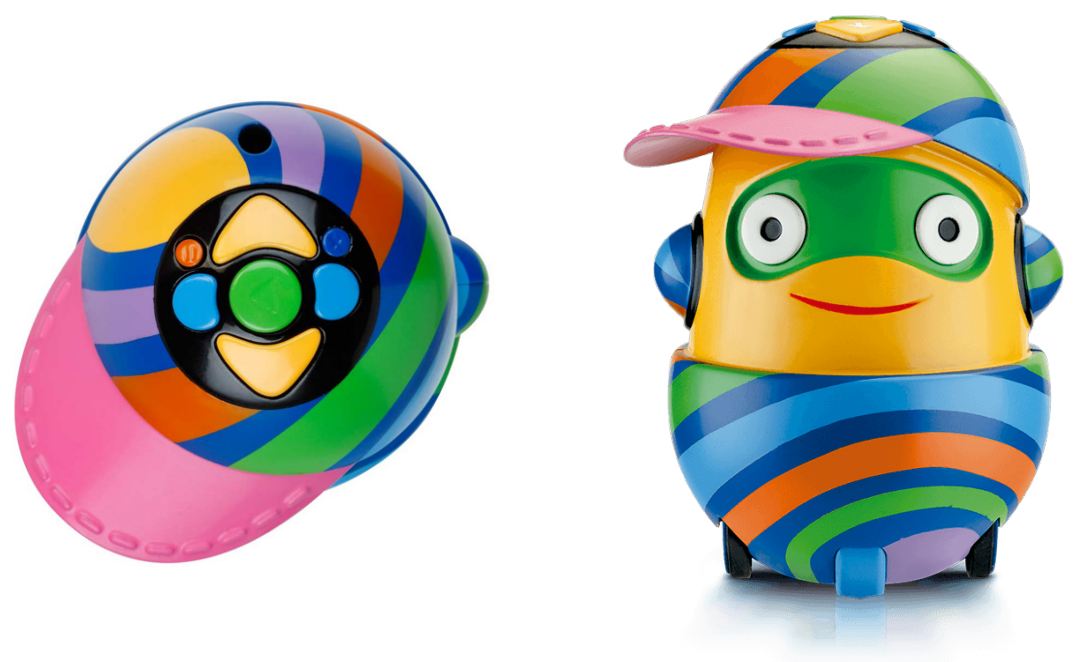

Figura 4. Robot Next 1.0

De esta forma, para trabajar con el robot, hemos proporcionado a los alumnos una plantilla elaborada por nosotras donde se encuentran impresos los diferentes animales marinos que hemos estado trabajando. Para llevar a cabo esta actividad, el rol del alumnado ha consistido en programar al robot para llevarlo al animal marino que les hemos indicado en la lengua extranjera. Por ejemplo; los docentes les hemos dicho: "Lets move to the shark"y el alumno ha tenido que programar el robot para llevarlo al animal marino que le hemos indicado. Los alumnos deben programar utilizando los botones que se muestran en la figura IV.

Con esta actividad, además de trabajar el vocabulario propio de la tarea (los animales del fondo marino), se han trabajado los colores (se encuentran presentes en los botones que deben utilizar para la programación del robot) y la lateralidad en la lengua extranjera puesto que, en ocasiones, los alumnos han necesitado ayuda de las maestras para llegar a su objetivo.

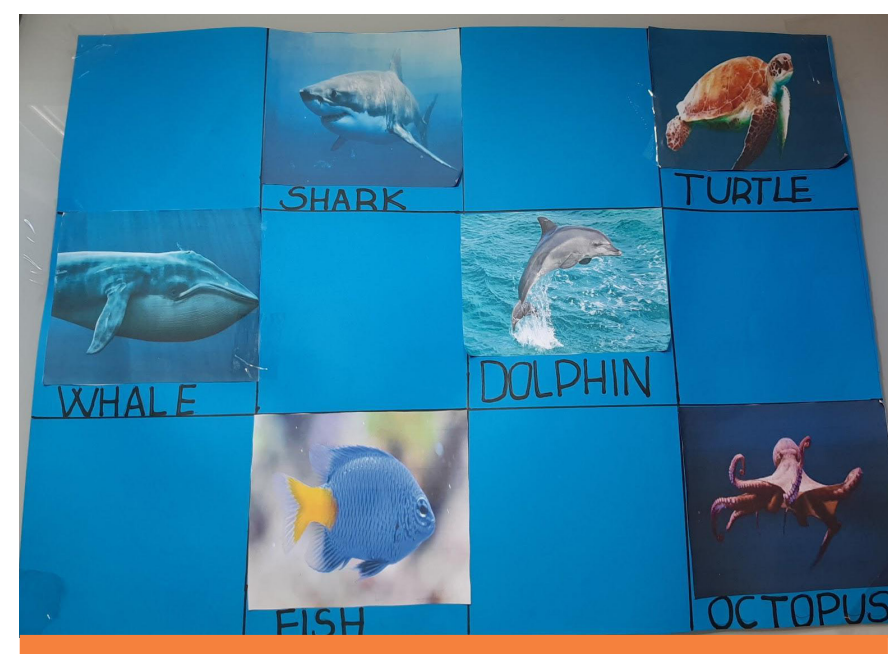

Figura 5. Plantilla sobre la que se ha trabajado en esta actividad 

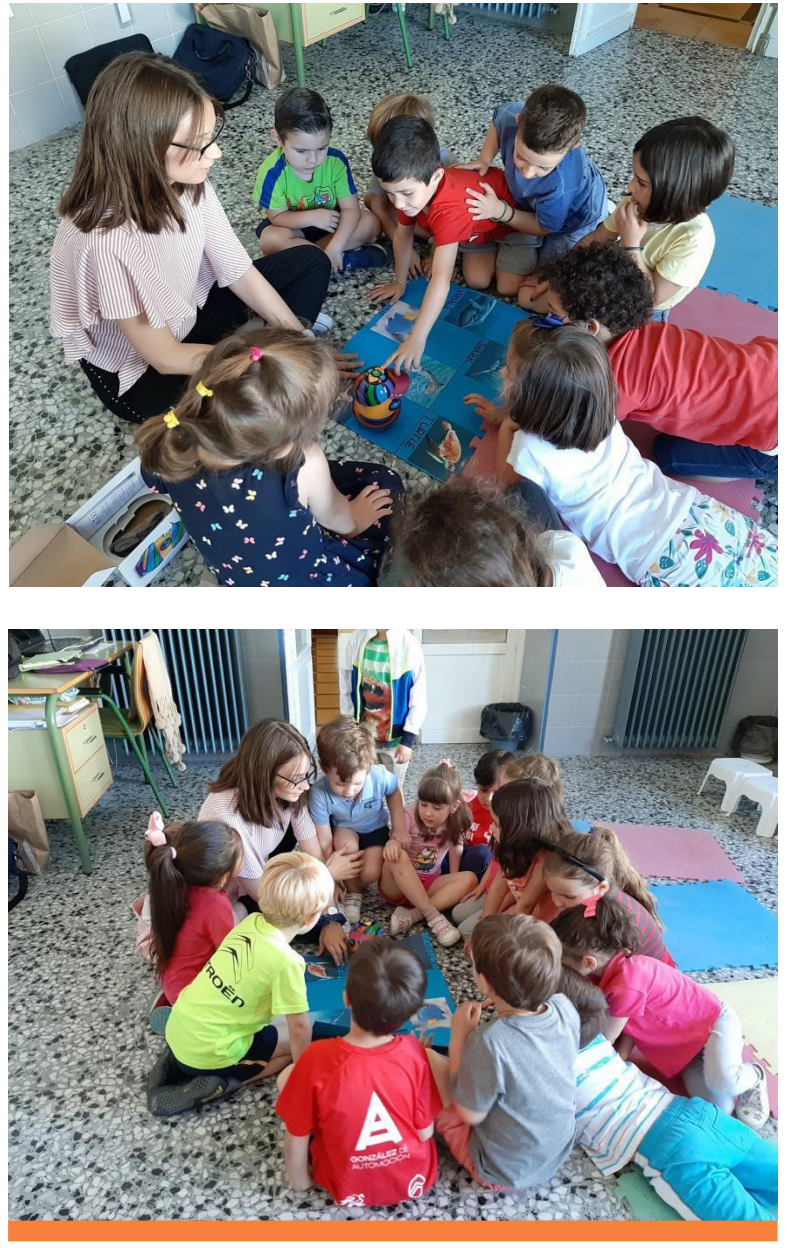

Figura 6. Puesta en práctica de la actividad con el Robot Next 1.0

\subsection{Tercera sesión: Educaplay y Kahoot}

En la última sesión hemos llevado a cabo dos tipos de actividades. La primera de estas actividades se ha realizado a través de la página web Educaplay la cual permite la creación de numerosos juegos educativos por parte del docente (mapas interactivos, crucigramas, concursos, etc). Entre esta variedad, para esta sesión hemos seleccionado una actividad que ha consistido en emparejar los diferentes animales marinos que hemos ido trabajando en la tarea. A través de esta página hemos podido crear un tablero donde tenemos diferentes cartas de animales marinos boca abajo, el objetivo principal de este juego es emparejar a estos animales, recordando dónde habíamos levantado su pareja. De esta forma, además de trabajar el vocabulario del fondo del mar con el alumnado, también hemos integrado estructuras gramaticales como: "Where is a shark?" "Are they different?" durante la actividad.
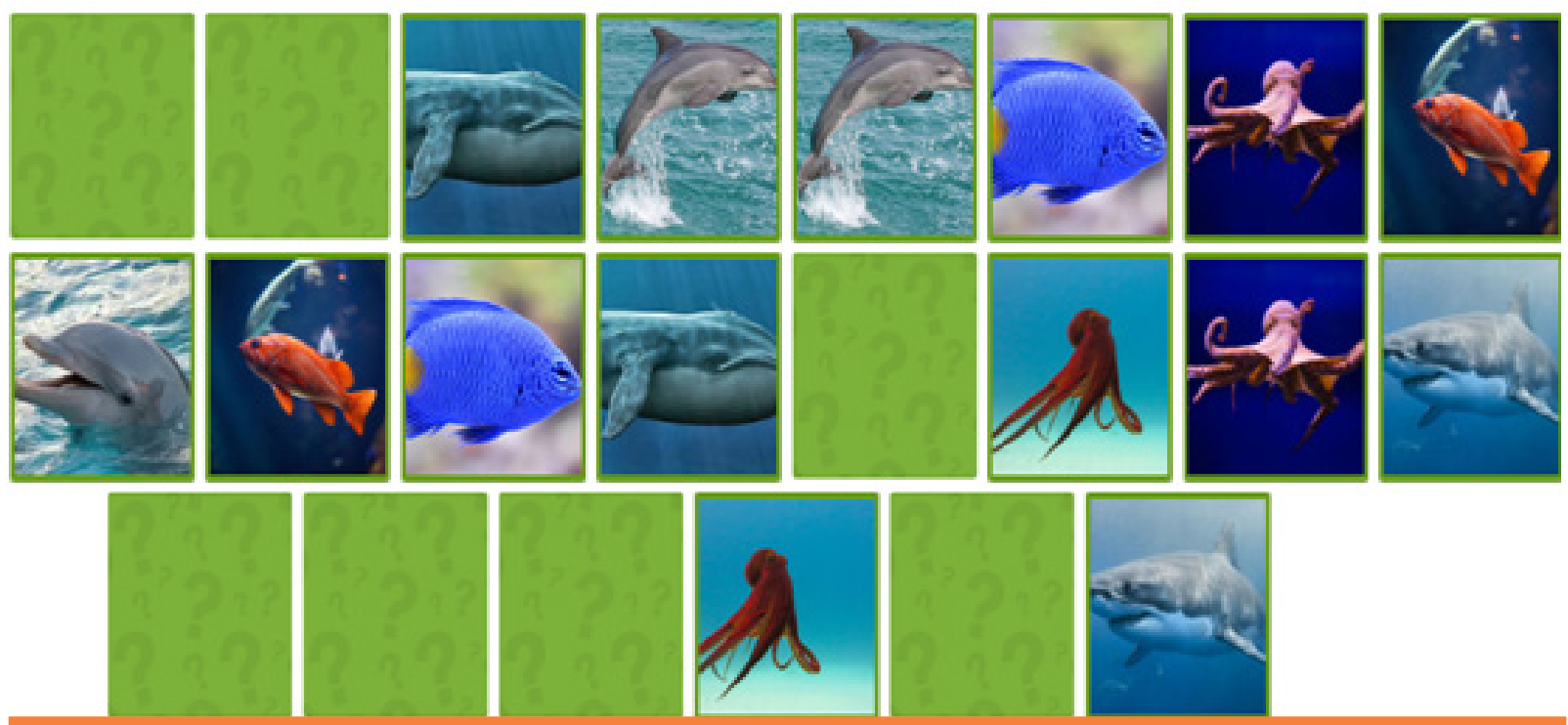

Figura 7. Tablero creado con Educaplay para emparejar los animales marinos 
Por último, la otra actividad que hemos llevado a cabo en esta sesión ha sido un cuestionario con Kahoot, esta aplicación permite realizar preguntas a los alumnos sobre el tema que se ha trabajado. De esta manera, se puede evaluar el proceso de enseñanza - aprendizaje de forma más lúdica para el alumnado. En el caso que nos ocupa, esta actividad se ha realizado con dos objetivos principales; el primero ha sido para conocer las actividades que más y qué menos les ha llamado la atención al alumnado implicado en esta práctica de innovación. Y el segundo objetivo ha sido para observar el grado de adquisición de los diferentes contenidos, concretamente del vocabulario relacionado con el fondo marino. Es de suma importancia destacar que a pesar de que nosotros, como docentes, hemos utilizado este recurso como un instrumento de evaluación, éste no debe sustituir el examen o debe dar la sensación al alumnado de ser una forma de evaluar, ya que, si esto ocurre, perderá su carácter lúdico.

\section{EVALUACIÓN DE LA EXPERIENCIA DE AULA}

Como hemos mencionado con anterioridad, la evaluación de esta experiencia ha sido realizada a través de la aplicación Kahoot. En la actualidad ya hay estudios que se muestran contrarios al uso de esta aplicación por su carácter competitivo entre el alumnado. Sin embargo, teniendo esta crítica en mente, hemos introducido Kahoot en las aulas de infantil obviando la parte competitiva, puesto que los alumnos han contestado a las preguntas de forma cooperativa, en grupos de cuatro o cinco alumnos y, además, como el objetivo principal de la actividad era la evaluación, no hemos incentivado la importancia de la puntuación obtenida, simplemente hemos observado las respuestas y actitud de los niños y niñas de acuerdo con una rúbrica de evaluación previamente diseñada. Los resultados de esta experiencia vienen recogidos en la siguiente gráfica (Gráfica 1: Actividades más y menos motivadoras para el alumnado de Educación Infantil).

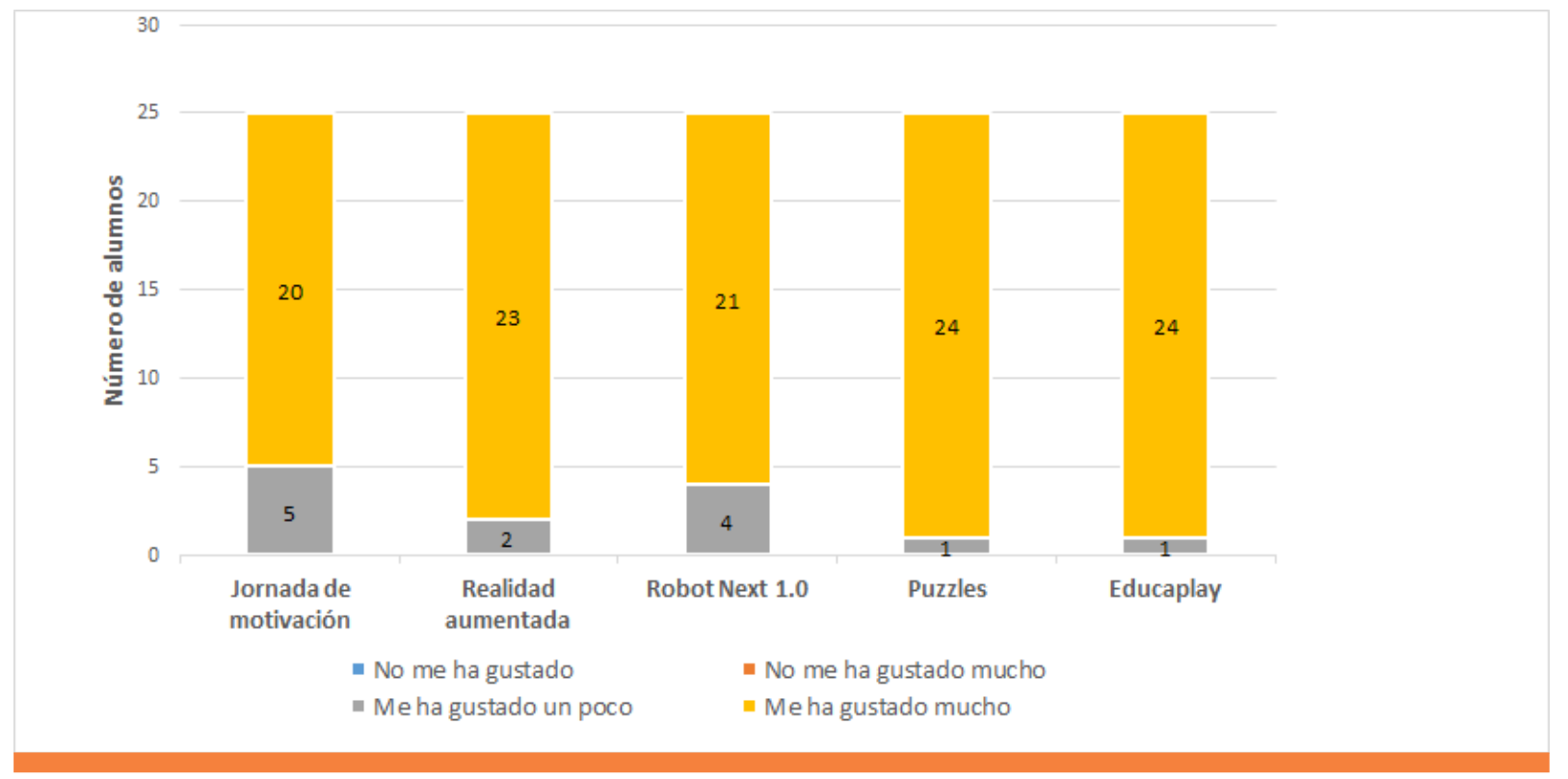

Gráfica 1. Actividades más y menos motivadoras para el alumnado de Educación Infantil 
Tras analizar los que nos ha proporcionado el alumnado a través de la aplicación Kahoot, hemos podido realizar la Tabla I, de la que podemos extraer las siguientes conclusiones. En primer lugar, podemos decir que las actividades en las que intervienen las nuevas tecnologías despiertan un gran interés en el alumnado. Dentro del conjunto de actividades, las más destacadas por los alumnos han sido aquellas en las que se han utilizado las tablets (Educaplay y Quiver) o el robot Next 1.0, en estas actividades un $90 \%$ aproximadamente del alumnado ha expresado su entusiasmo o las ha recordado como la actividad que más les ha gustado. Cabe mencionar también que la actividad que menos ha destacado en el momento de la evaluación ha sido la actividad de presentación, en la cual proyectamos un mensaje a través de la aplicación Voki. Podemos concluir diciendo que las actividades en las que se ha usado el robot o las tablets destacan por la oportunidad que se les ofrece a los alumnos de manipular los diferentes elementos TAC y, de esta forma, de sentirse el centro y protagonistas de su aprendizaje.

Por otro lado, el uso de la metodología CLIL ha permitido que el alumnado, con tan solo tres sesiones de 45 minutos, sea capaz de identificar el vocabulario que nos marcamos como objetivo, usar las estructuras gramaticales propuestas e incluso, identificar en el lenguaje escrito el vocabulario que le hemos presentado. Este último logro no formaba parte de los objetivos principales del proyecto, pero a través del uso de los flashcards, los alumnos han sido capaces de identificar las grafías de cada animal del fondo del mar que le hemos presentado.

Cabe destacar que los resultados no pueden ser considerados concluyentes puesto que aspectos como el conocimiento previo de los alumnos, las capacidades que presentan estos o el número de agentes implicados no se han evaluado en profundidad. Sin embargo, los resultados obtenidos avalan la fundamentación teórica del presente trabajo. Concordando así la práctica con lo que expone Marsh (2002, p.1) sobre CLIL, considerando esta metodología como una guía hacia el plurilingüismo, posibilitando utilizar al menos dos lenguas en la enseñanza de los contenidos curriculares. Por otro lado, los resultados también coexisten con lo expresado por la UNESCO (Pinargote \& Ramirez, 2018, p. 3) sobre la importancia que supone el uso de las nuevas tecnologías en las aulas infantiles.

Por último, cabe mencionar las limitaciones y dificultades que se han detectado en la puesta en práctica de esta tarea:

- El uso de dispositivos móviles por parte del alumnado requiere de una atención mayor del maestro hacia el alumnado, y la ratio de las aulas de la mayoría de centros educativos no permite esta atención más individualizada y constante. Algo semejante sucede con la metodología CLIL, donde los alumnos necesitan mayor atención y más oportunidades de expresión.

- Por otro lado, para poder llevar a cabo este tipo de actividades se necesita una gran cantidad de material TAC. Esta necesidad supone una importante inversión económica por parte del centro.

- Por último, mencionar la importancia de la formación del profesorado. Tanto para impartir la metodología CLIL como para utilizar los recursos TAC, es necesario un profesorado en continuo reciclaje y aprendizaje. 
A pesar de las limitaciones ya mencionadas, tanto las nuevas tecnologías comola metodología CLIL son un medio de enseñanza-aprendizaje que presenta numerosos beneficios en la etapa de Educación Infantil. Por un lado, la metodología CLIL facilita la adquisición de la lengua extranjera de forma más comunicativa y significativa para el alumnado y por otro lado, el uso de las TAC permite que este aprendizaje sea más lúdico, motivador y cercano a la realidad de los alumnos.

\section{CONCLUSIONES}

Como se ha mencionado a lo largo del trabajo, el objetivo principal de esta innovación es integrar las nuevas tecnologías y la metodología CLIL en los proyectos de trabajo de los alumnos de la etapa de Educación Infantil. De esta forma, el alumnado aprenderá los contenidos presentes en el currículum de educación infantil a través de CLIL, siendo el vehículo comunicativo la lengua extranjera. Además, se ha pretendido implementar un factor motivador para el aprendizaje, el uso de las TAC.

Sin embargo, es importante tener en cuenta, por un lado, que el uso de las tecnologías no debe eclipsar a la metodología de enseñanza - aprendizaje como puede el uso de métodos de investigación, manipulación o experimentar con los objetos reales, presentes en su entorno. Dicho de otra manera, es importante mantener el equilibrio entre el uso de las actividades TAC con actividades donde el alumno interaccione con el medio, resuelva problemas, investigue, manipule, etc. En conclusión, podríamos decir que las nuevas tecnologías no deben ser el fin educativo si no que deben ser un elemento, un recurso más para motivar y guiar a los alumnos en su proceso de aprendizaje.

Por otro cabe mencionar dos aspectos básicos; el primero de ellos es que el uso de la lengua extranjera no interfiere en el aprendizaje de los contenidos ni en la adquisición de la lengua materna, los alumnos inmersos en esta metodología son capaces de comprender los contenidos sin grandes dificultades, aunque se debe tener en cuenta que si existe una falta de comunicación y comprensión se puede recurrir al uso de la lengua materna. Y el segundo aspecto se relaciona en cómo a través de usar la metodología AICLE se crean contextos comunicativos reales en los que es necesario usar la lengua extranjera. De esta forma, los alumnos adquieren un mayor dominio de la lengua extranjera a través de situaciones reales de comunicación.

\section{REFERENCIAS}

Bers, M. U. (2008). Blocks, robots and computers: Learning about technology in early childhood. New York: Teachers College Press.

Bers, M. U., Horn, M. S. (2010). Tangible Programming in Early Childhood: Revisiting Developmental Assumptions Through New Technologies. En I. R. Berson y M. J. Berson (Eds.), High-Tech Tots: Childhood in a Digital World (49-70). (Research in Global Child Advocacy). Information Age Publishing.

Brown, H. D. (2006). Teaching by principles: An interactive approach to language pedagogy (5a ed.). White Plains, NY: Longman. 
Coalla, S. (2014). TIC y nuevas tecnologías en AICLE: un estudio práctico. Trabajo Fin Máster en enseñanza integrada de la lengua inglesa y contenidos: educación infantil y primaria. Universidad de Oviedo: Oviedo.

Coyle, D. (2002). Relevance of CLIL to the European commission's language learning objectives en D. Marsh, (Ed.), CLIL/EMILE-The European Dimension: Actions, Trends and Foresight Potential Public Services Contract DG EAC. European Commission: Strasbourg.

Coyle D. (2008) CLIL -A Pedagogical Approach from the European Perspective. En Hornberger N.H. (Eds.) Encyclopedia of Language and Education. Springer: Boston. https://doi.org/10.1007/978-0-38730424-3_92

Coyle, D., Hood, P., Marsh, D. (2010). CLIL: Content and Language Integrated Learning. Cambridge University Press: Cambridge

Loyola, D. (2013). Análisis de CLIL (Content Language Integrated Learning) como metodología para enseñar inglés como segunda lengua. (Tesis doctoral). UNIR.

Marsh, D. (2002). ¿Qué es CLIL?. Recuperado a partir de: https://bit.ly/2HHQGAT

Marsh, D. (2000). Using languages to learn and learning to use languages: An introduction to content and language integrated learning for parents and young people en Marsh y Langé. (Eds.). Jyväskylä, Finlandia/Milan, Italia: TIE-CLIL, University of Jyväskylä/Ministero de Pubblica Istruzione.

Mehisto, P., Marsh, D. y Frigols-Martín, M. J. (2008). Uncovering CLIL: Content and language integrated learning in bilingual and multilingual education. Oxford, UK:Macmillan Education.

Moreno, E. y Pérez, A. (2017). La realidad aumentada como recurso didáctico para los futuros maestros. (17), 42-59. Recuperado a partir de https://bit.ly/3mg4eSY

Orcera Expósito, E., Moreno Fuentes, E., y Risueño Martínez, J. J. (2017). Aplicación de las TAC en un entorno Aicle: una experiencia de innovación en Educación Primaria. Aula De Encuentro, 19(1). Recuperado a partir de https://bit.ly/3mbLpjP 